Bilingualism: Language and

Cognition

\section{cambridge.org/bil}

\section{Erratum}

Cite this article: Czapka S, Wotschack C, Klassert A, Festman J (2020). A path to the bilingual advantage: pairwise matching of individuals-CORRIGENDUM - ERRATUM. Bilingualism: Language and Cognition 23, 231-231. https://doi.org/10.1017/ S1366728919000713

First published online: 31 October 2019

\title{
A path to the bilingual advantage: pairwise matching of individuals-CORRIGENDUM - ERRATUM
}

\author{
Sophia Czapka, Christiane Wotschack, Annegret Klassert and Julia Festman
}

https://doi.org/10.1017/S1366728919000336, Published by Cambridge University Press,

When originally published, the article by Czapka et al, included the wrong caption for Fig 2. The publication indicates that Fig 2 shows data for heterogeneous groups when in fact it shows data for homogenous groups.

The correct figure and caption is shown below

A corrigendum has been previously published incorrectly stating that the problem lies with Fig 1. Fig 1 is correct in the original published article
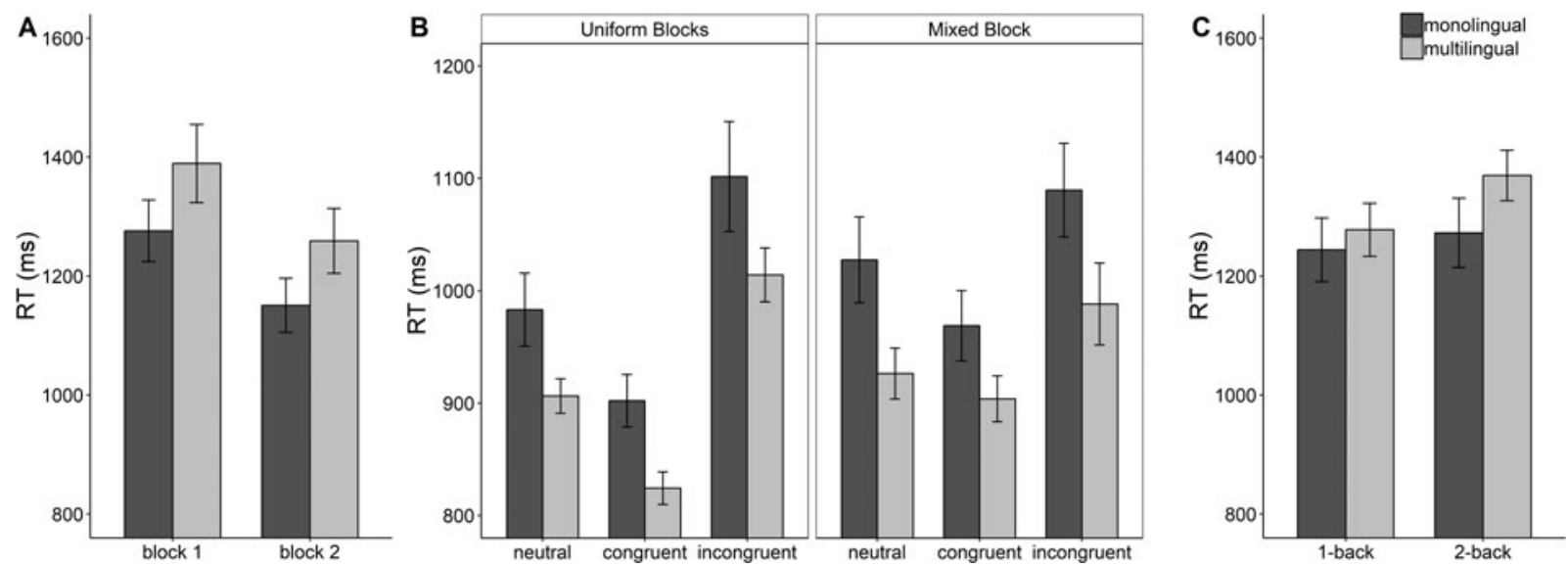

Fig. 2. Mean response latencies (with error bars indicating standard errors) of the A) go/nogo task, B) BST and C) N-back for the homogenous groups (monolinguals dark bars and multilinguals - light bars).

\footnotetext{
(c) The Author(s) 2019. This is an Open Access article, distributed under the terms of the Creative Commons Attribution licence (http:// creativecommons.org/licenses/by/4.0/), which permits unrestricted re-use, distribution, and reproduction in any medium, provided the original work is properly cited.
}

\section{References}

Czapka S., Wotschack C., Klassert A., \& Festman J. (n.d.). A path to the bilingual advantage: Pairwise matching of individuals. Bilingualism: Language and Cognition, 1-11. doi:10.1017/S1366728919000166

Czapka S., Wotschack C., Klassert A., \& Festman J. (n.d.). A path to the bilingual advantage: Pairwise matching of individuals- CORRIGENDUM. Bilingualism: Language and Cognition, 1-1. doi:10.1017/S1366728919000336 